\section{Hard times for DFG}

\section{Munich}

THE Deutsche Forschungsgemeinschaft (DFG) announced last week that it will be able to fund only 14 of the 30 'priority programmes' (Schwerpunktprogramme) applied for by university researchers. Priority programmes support collaborative projects in social and natural sciences as well as engineering for up to five years.

Projects were approved by the DFG Senate on 28 November in fields ranging from market economics to "genome analysis and gene transfer in domestic animals". A further nine projects deemed worthy of funding were rejected because of a lack of money. A witness to the Senate session said it resembled an "oriental bazaar", with Senate members desperately swapping proposals, trying to support as many as they could. In the end they were satisfied that at least a few good proposals were funded.

Until a few years ago, all qualified proposals for priority programmes were funded. This is the first time that fewer than half of these priority programmes could be supported. The number of applications reached an all-time high this year. DFG officials once again warned of the discouraging effects on researchers if more government money does not become available.

Steven Dickman

\section{Less school science}

\section{London}

THE amount of time that pupils at UK secondary schools spend studying science is the subject of the latest controversy to follow from the 1988 Education Reform Act. A working group on science set up by Mr Kenneth Baker, Secretary of State for Education and Science, recommended that in the fourth and fifth years of secondary school, pupils should spend 20 per cent of their time on science and aim for two GCSE exam certificates. But Baker asked the National Curriculum Council (NCC) to draw up a plan allowing some pupils to devote only $\mathbf{1 2 . 5}$ per cent of their time to science and aim to get just one certificate. In its report published this week, the NCC has outlined such a plan, but recommends that pupils should aim for the fuller programme, as the reduced one is lacking in breadth. Baker is expected to make draft orders following the NCC's advice before next year.

Mr Jack Straw, education spokesman for the Labour Party, says that Baker's plan is an "easy, cheap, but short-term way out of mounting shortages of science and maths teachers". And he cites figures which show that most of the universities and polytechnics which commented on the proposals of the working group are opposed to Baker's plan.

\title{
Difficulties ahead for Japan's fifth-generation computer plan
}

Tokyo

JAPAN's Institute of New Generation Computer Technology (ICOT) is about to make a final spurt towards its goal of building a fifth-generation computer. The institute unveiled the fruits of seven years' work at its international conference in Tokyo last week along with plans for a final three-year push. But critics wonder whether ICOT can reach its target or even if it is headed in the right direction.

The Ministry of International Trade and Industry (MITI) sent shock waves through the computing world in 1981 when it announced plans to develop an entirely new generation of "user friendly", intelligent computers. Although the computers are not yet in sight, ICOT director Kazuhiro Fuchi was brimming with confidence at last week's conference. He says the research has been "smoothly conducted so far" and ICOT is ready to "jump" into the final phase of the project.

MITI has requested $¥ 6,448$ million ( $\$ 52$ million) for ICOT in fiscal 1989, 12.5 per cent more than this year. And Fuchi hopes to get more than $¥ 20,000$ million for the final three years of the project (1989 to 1991) which will concentrate on building a massive parallel inference machine (PIM) and accompanying software. PIM will contain 1,000 individual processing elements and be capable of 100 to 1,000 million logical inferences per second, far beyond the capabilities of present computer technology.

But many difficulties lie ahead. At the conference a system of 64 sequential inference machines linked in a network was on display but ICOT researchers admit that preparation of software for the system was much more complicated than anticipated. David Warren, an expert on parallel computing from the University of Bristol, says that the biggest technical barrier to be overcome is the development of software for PIM. ICOT's approach is for the programmer to specify explicitly how the computational problem and subproblems should be divided up. But Warren points out that parallelism should be hidden from the programmer if the computer is to be "user friendly", otherwise it can be programmed only by experts.

One of the key features of the computer originally foreseen by ICOT was an intelligent man-machine interface that would allow communication by speech and drawings. But, according to Hideo Aiso, the conference chairman, image-processing and speech-recognition were dropped in 1985 because of budget restrictions and lack of manpower.

Another line of research that has disappeared involves the knowledge-based system at the core of the machine. ICOT took the unusual approach of trying to develop hardware rather than software for the storage and retrieval of knowledge. And at ICOT's last international conference in 1984 a prototype relational database 'machine' called Delta was displayed with much fanfare.

Nothing has been heard of Delta since. A public relations officer for ICOT says a new Delta machine will be built in the final' phase of the project. Warren says ICOT has clearly decided to pursue development of knowledge-base software rather than hardware. But virtually no work has been done on parallelization of knowledge processing so this will be a major challenge for the final phase.

Fuchi admits that there are many problems to overcome. But he says that by taking up the challenge "human beings will be forced to come up with an answer", though he says the chances of successfully developing PIM are just 50 per cent.

Many particpants at the conference question whether ICOT has chosen the right approach by sticking rigidly to logic programming and parallel processing. Competing projects in Europe and the United States, such as ESPRIT (European Strategic Programme for Research and Development in Information Technology) and DARPA (Defense Advanced Research Project Agency), have adopted a much more diversified approach and are, for example, branching out into neural network computing.

Warren says, however, that ICOT's project should not just be judged on whether it achieves its goals. The project has succeeded in "plugging Japanese computer researchers into the world research commmunity" and is making a substantial contribution to basic research. PIM may not be the best approach, he says, but given that ICOT must come up with a machine in three years, it is probably the best way to go.

-Britain's Information Engineering Directorate (IED) and Japan's Institute for New Generation Computer Technology (ICOT) have reached an agreement that will allow IED researchers to carry out long-term research at ICOT.

The agreement, announced at the conference, will enable two IED researchers to spend from six months to one year in Japan. An earlier attempt to arrange cooperation between scientists involved in the UK's Alvey project and ICOT fizzled out because of problems associated with patent rights. Under the present agreement, intellectual property rights will be will worked out on a "caseby-case" basis. David Swinbanks 